\title{
FTIR analysis and monitoring of used synthetic oils operated under similar driving conditions
}

\author{
Artur WOLAK ${ }^{1, *}$, Wojciech KRASODOMSKI ${ }^{2}$, Grzegorz ZAJĄC ${ }^{3}$ \\ ${ }^{1}$ Department of Quality and Safety of Industrial Products, Institute of Quality and Product Management Sciences, Cracow University of \\ Economics, Kraków 30-033, Poland \\ ${ }^{2}$ Department of of Petroleum Analyses, Oil and Gas Institute-National Research Institute, Kraków 31-503, Poland \\ ${ }^{3}$ Department of Power Engineering and Transportation, Faculty of Production Engineering, University of Life Sciences in Lublin, Lublin \\ 20-612, Poland
}

Received: 31 October 2019 / Accepted: 19 November 2019

(C) The author(s) 2019.

\begin{abstract}
The processes of degradation of engine oils operated in passenger cars of a uniform fleet of 25 vehicles were analyzed for oxidation content using infrared (IR) spectroscopy. As part of the experiment, the changes in engine oils occurring during actual operation (under conditions which can be described as "harsh", i.e., short distance driving, frequent starting of the engine, and extended engine idling) have been observed. An evaluation of the Fourier transform infrared spectroscopy (FTIR) spectrum of an engine oil sample was presented. The infrared spectra of both fresh and used oils were recorded with the Thermo Nicolett IS5. The tests were conducted according to the Appendix A2 of ASTM 2412. For the used engine oil differentiation process, FTIR spectra were analyzed in the regions of 1,700-2,000 $\mathrm{cm}^{-1}$ and 3,600-3,700 $\mathrm{cm}^{-1}$. The FTIR spectrometry is demonstrated to be effective for the analysis and monitoring of processes of oxidation and shown to provide rapid and accurate information relating to the aging process of engine oils. The results may facilitate decision-making regarding the service life of engine oils. The achieved dependencies can make it possible to upgrade the sensor assembly consisting of an FTIR source.
\end{abstract}

Keywords: Fourier transform infrared spectroscopy (FTIR); reliability; modelling; oil condition monitoring; oil oxidation; oil change interval

\section{Introduction}

The heat generated during operation of the engine as well as the contact with fuel and its combustion products, together with the presence of oxygen from air, cause degradation of the basic component of motor oils-hydrocarbons. The accompanying chemical and mechanochemical transformations result in the depletion of refining additives that give the engine oil the required qualitative characteristics. One of the parameters characterizing the degradation occurring as a result of high temperature interaction between the oxygen present in the combustion chamber and the components of engine oil is the degree of oxidation.

The Fourier transform infrared spectroscopy (FTIR) is commonly used for evaluating the condition of oils in terms of such parameters as oxidation, nitration, water content, and soot content [1]. Since the 1990s, research has been conducted on the effective application of FTIR to assess TAN, TBN, or viscosity. The FTIR methods are usually applied to control the oil degradation processes during engine use, especially changes in their oxidation level. Infrared spectroscopy has long played a key role in lubricant analysis aimed at characterizing qualitatively its different constituents. The IR spectroscopy belongs to the group of instrumental

* Corresponding author: Artur WOLAK, E-mail: artur.wolak@uek.krakow.pl 


\begin{tabular}{llll}
\multicolumn{2}{l}{ List of symbols } & & \\
FTIR & Fourier transform infrared spectroscopy & CE & Oil group code-selected for the test \\
ASTM & American Society for Testing and Materials & ME & Oil group code-selected for the test \\
ERP & Electron paramagnetic resonance & MS & Oil group code-selected for the test \\
AW/EP & Anti-wear and extreme pressure additives & PE & Oil group code-selected for the test \\
ZnDDP & Zinc dialkyldithiophosphates additive & PS & Oil group code-selected for the test \\
PCA & Principal component analysis & $\bar{x}$ & Arithmetic average \\
TAN & The total acid number & $S$ & Standard deviation \\
TBN & The total base number & CV & Coefficient of variation \\
SAE & Society of Automotive Engineers & $p$ & Value resulting from application of \\
ACEA & European Automobile Manufacturers' & & Student's test \\
& Association & $P$ & Single point predictive \\
API & The American Petroleum Institute & $P_{\mathrm{d}}$ & Lower limit of the $95 \%$ prediction interval \\
PPR & Projection pursuit regression & $P_{\mathrm{g}}$ & Upper limit of the $95 \%$ prediction interval \\
RF & Random forest & $G$ & The limit value
\end{tabular}

analysis methods and is based on studies of electron spectra of chemical compounds containing specific chemical bonds in the molecule. It is also a method used to determine the content of some chemical compounds in mixtures in which the measurement is made at a fixed wavelength. The FTIR method is used to describe oil aging, which results from the operating conditions and the occurrence of three processes: oxidation (the attachment of oxygen to hydrocarbons contained in oil, band 1,660-1,800 $\mathrm{cm}^{-1}$ - carbonyl bonds), sulfonation (the attachment of sulfur oxide, band 1,150 $\mathrm{cm}^{-1}$-the sulfonation/oxidation groups), and nitration (the attachment of nitrogen oxide, 1,610$1,650 \mathrm{~cm}^{-1}$ - the nitro groups).

In recent years, several online sensors for measuring lubricant properties have been developed and used by researchers and the industry [2-4]. This is done to ensure the required operational properties of the lubricating oil by verifying the intervals of its replacements depending on the operating conditions (which, in turn, are closely related to the quantitative and qualitative processes of lubricating oil degradation). The analysis of the quality of oils based on infrared spectroscopy has been undertaken by many scientists [3, 5-15].

The FTIR spectrometry makes it possible to determine various oil properties, such as oxidation, nitration, and sulfation. However, the most important parameter is the oxidation number, which is a measure of the oxidative degradation of oil [16]. Hence, the purpose of the present research was to develop a statistical model describing the intensity of changes in the oxidation of engine oils using FTIR technique. The research findings may be helpful in assessing engine oil behavior during its use. The achieved dependencies can make it possible to upgrade the sensor assembly consisting of an IR source. Furthermore, a model based on changes in oil properties under real operating conditions has been proposed, thus also providing more information about FTIR application. The estimated regression equation in the form of $Y=$ $A+B X$, enables to calculate average predictive values for the level of oxidation $(Y)$ and given mileage $(X)$. The conducted experiment was an original idea (all in-service lubricants were tested in identical cars and in the same period of time). The cars used in the study were a consistent fleet, in terms of brand, type, and operating conditions. The changes in engine oils occurring during actual operation have been thoroughly examined.

\section{Materials}

Engine oils produced by five different manufacturers were used in the tests. The oils were applied in 25 vehicles, normally used for car driving tests (each 
type of oil to 5 vehicles). All vehicles were equipped with $1.33 \mathrm{dm}^{3}$ petrol engines and driven in urban environment (except for two as described below). The engine oils selected for the tests met the quality requirements of the car manufacturer and belonged to the same 5W-30 quality class. The specifications of oils and their individual code names are shown in Table 1.

As many as 23 cars from the whole fleet were operated in urban driving conditions, oftentimes over short distances, with extended periods of idling and frequent engine start/stop. Such mode of operation may be referred to as "harsh". The remaining two vehicles (coded: CE 017977 and PS 018193) were used in typical mixed driving conditions, i.e., much milder ones. However, two cars did not comply with the requirements for being driven in similar conditions, which resulted in their exclusion from statistical analysis, and the viscosity determination of these oils was made only for comparative purposes.

In order to ensure the representativeness of the samples, an appropriate sampling frequency was set for the entire course of the testing so as to avoid excessive loss of oil and the need to top it up. Following the recommendations of the car fleet owner, the oil was replaced every year regardless of the number of kilometers traveled; therefore, it was decided that the samples would be collected regularly every 3 months (quarter of the year) starting from the moment of oil change. The volume of the monitored sample did not exceed $0.2 \mathrm{dm}^{3}$, as the frequent sampling of engine oil and a larger sample volume might make it necessary to refill the oil and thus distort the overall test results. After the first two stages of testing, two of the vehicles were decommissioned for reasons unconnected with the research. As a result, in the $1^{\text {st }}$ and $2^{\text {nd }}$ quarter 25 samples were collected, whereas in the $3^{\text {rd }}$ and $4^{\text {th }}$ 23 samples were collected. In total, 96 samples were obtained during the entire period of testing. The number of kilometers traveled by each car varied depending on the frequency of use of each vehicle. The average number of kilometers traveled by cars in each oil group are shown in Table 2. The mileage of the vehicles (as covered during the experiment) is shown in Ref. [17].

\section{Research methodology}

FTIR method was used to analyze changes in the degree of oxidation of engine lubricating oils, i.e., to assess the oil quality changes by analyzing the oil spectrum in infrared light. The IR spectroscopy belongs to the group of instrumental analysis methods and is based on studies of electron spectra of chemical compounds containing specific chemical bonds in the molecule. It is also a method used to determine the content of some chemical compounds in mixtures, in which the measurement is made at a fixed wavelength. The chemical composition of the fresh and used motor oils was investigated by comparing their FTIR spectra. The levels of individual bands for the used oils were determined not directly from their spectra, but from the differential spectra, i.e., spectra generated as a result of the mathematical operation: the spectrum of the used oil minus the spectrum of fresh oil. The FTIR charts for selected samples from each oil group are shown as examples of FTIR variations for each oil type.

On the basis of the obtained oil spectrum, the signal measurement was analyzed in the appropriate area of absorption of infrared radiation $1,660-1,800 \mathrm{~cm}^{-1}$ (carbonyl bonds). The levels of oxidation, i.e., changes in absorbance of the carbonyl bonds in used oils spectra, were determined from the difference spectra (the spectra obtained from the subtraction of the spectrum of used oil and the spectrum of fresh oil).

Oil condition monitoring can be properly assessed using multiple parameters. All of the most crucial factors (such as viscosities-kinematic, dynamic, cranking [17, 18], TAN [19], TBN [20], nitration, content

Table 1 Specifications of the engine oils used in the research.

\begin{tabular}{cccccc}
\hline & & & Oil code & \\
Classification & CE & ME & MS & PE & PS \\
\hline SAE & $5 \mathrm{~W}-30$ & $5 \mathrm{~W}-30$ & $5 \mathrm{~W}-30$ & $5 \mathrm{~W}-30$ & $5 \mathrm{~W}-30$ \\
ACEA & $\mathrm{A} 3 / \mathrm{B} 3-10, \mathrm{C} 3-10$ & $\mathrm{C} 2 / \mathrm{C} 3-10$ & $\mathrm{C} 3-10$ & $\mathrm{C} 2-10$ & $\mathrm{~A} 3 / \mathrm{B} 3-10$ \\
API & $\mathrm{SH}$ & $\mathrm{SM} / \mathrm{SN}$ & $\mathrm{SM} / \mathrm{SL}$ & - & $\mathrm{SM}$ \\
\hline
\end{tabular}


Table 2 The mean values, standard deviations, and * $p$ values after specific periods of measurement.



$N$ - the number of samples tested, $x$-arithmetic average, $s$-standard deviation, ${ }^{*} p$-value resulting from the application of Student's $\mathrm{t}$ test for dependent samples.

Oil groups (i.e., CE-ME) mean a juxtaposition of two differential oil groups. A comparison of results for individual groups allows to indicate similar oils or oils that differ.

of elements, and foam [21]) were measured for the purposes of this research. Oxidation is one of several indicators of oil degradation which have been analyzed. The study produced a comprehensive range of data which formed the basis for other research papers and publications that have already been published [17-21] or are now being reviewed and edited.

To determine changes in the engine oil during its use, the FTIR spectra were interpreted in the regions of 3,600-3,700 $\mathrm{cm}^{-1}$ and $1,700-2,000 \mathrm{~cm}^{-1}$. The infrared spectra were registered with the Thermo Nicolett IS5 (using FTIR method). The investigations were performed using the Appendix A2 of ASTM 2412. The details regarding conducted measurements and applied statistical apparatus were described in Ref. [17].

\section{Presentation and analysis of study results}

The chemical character of fresh and used engine oils was explored by analyzing their FTIR spectra. The variations of FTIR spectra of selected samples from every oil group are shown below (Fig. 1). Since the obtained research material was very comprehensive (25 cars), it would be difficult to fit spectra for all tested oils; therefore, it was decided to present the results in the form of aggregate charts (Fig. 2). The FTIR differential spectra and the absorbance values within ranges which are typical of antioxidant depletion $\left(3,700-3,500 \mathrm{~cm}^{-1}\right)$ as well as oxidation products $(2,000$ $1,700 \mathrm{~cm}^{-1}$ ) are shown in the graphs below. The monitoring of used lubricants by applying infrared spectroscopy has been described in numerous papers, whose authors have shown that the bands in the range of $1,660-1,800 \mathrm{~cm}^{-1}$ are associated with the formation of oxidation products, e.g., Refs. [22-26]. That is why, the spectra were analyzed in that particular range $\left(1,660-1,800 \mathrm{~cm}^{-1}\right)$. The results of the research have shown that the changes taking place over time in all oil groups have an almost linear character in all of the cases (Fig. 2). In the engine oils from the PS group, a 



Fig. 1 FTIR differential spectra for each group of samples, the regions $3,600-3,700 \mathrm{~cm}^{-1}$ and $1,700-2,000 \mathrm{~cm}^{-1}$.

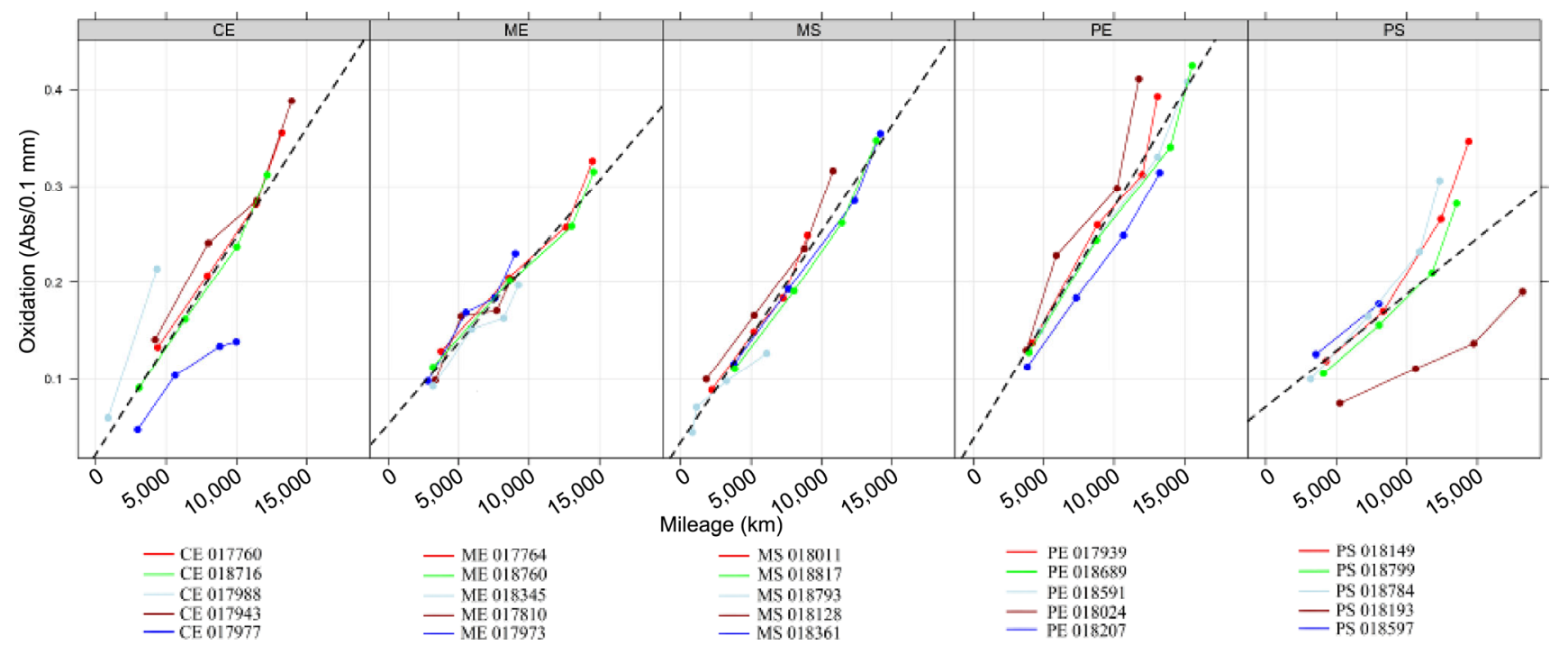

Fig. 2 Changes in engine oil oxidation levels.

milder increase in the degree of oxidation was initially observed (to the level of $8,000 \mathrm{~km}$ ), whereas above this level the oxidation process was intensified. The lowest resistance to oxidation was found in oils from the PE group while the ME and PS oils showed slightly better resistance to oil degradation caused by oxidation. Among the used oils, the largest percentage increase from the first to the second quarter was observed for the following oils: CE 017988-258\% increase (from 0.06 to 0.21 (Abs/0.1mm)), CE $017977-116 \%$ increase (from 0.05 to $0.10(\mathrm{Abs} / 0.1 \mathrm{~mm})$ ) and PE $018689-90 \%$ increase (from 0.13 to 0.24 (Abs/0.1mm)). From the first to the fourth quarter, more than two fold increase was noted for three oils from the MS group (MS 018817 (212\%), MS 018128 (215\%), MS $018361(205 \%))$, for two oil samples from the PE group (PE 018689 (231\%), PE 
$018024(216 \%))$, for one oil from the CE group (CE $018716(243 \%))$ and one from the PS group (PS 018784 (206\%)). Among all of the oil samples tested, the slowest rate of oxidation was observed for CE 017977 (reaching the oxidation level of 0.14 (Abs/0.1mm) after nearly 10,000 km), and PS 018193 (reaching the level of 0.11 (Abs $/ 0.1 \mathrm{~mm}$ ) after the same number of kilometers traveled).

The oxidation of oil leads to major changes in its viscosity [17] and to premature aging. It also limits the lubricating ability of oil, as the number of kilometers traveled goes further up. The oil's lifespan and how its lubricating ability is limited by the number of kilometers traveled by a vehicle have been thoroughly described in several papers focusing on the use of lubricants. Typically, to predict the engine oil's lifespan, the Shewhart's charts are used, e.g., Refs. [27, 28])

The two oil samples CE 017977 and PS 018193, deserve a more careful analysis in relation to the extent to which changes in operating environment have affected the variations in oxidation level. Significantly lower oxidation levels (ca. 40\%, when compared with the oils from the first group), lower kinematic viscosity value (ca. $10 \%$ ) as well as a lower TAN value (ca. $30 \%$ ) [19] were obtained for these two samples throughout the whole experiment [17].

Table 2 provides more detailed information about the examined engine oils in subsequent measurement intervals. The significance level was established at 0.05 . $p$-values under this threshold were deemed statistically significant (given in bold) and $p$-values smaller than 0.01 were considered highly significant (underlined and given in bold).

Upon analyzing the separate variables presented in Table 2, it was found that after the first measurement period, all tested oils, with the exception of the PE and MS oil pair, can be considered homogeneous in terms of the degree of oxidation. The analysis of the variable, vehicle mileage, has already been described in detail in the research paper devoted to the changes in kinematic viscosity [17], which is why it will be omitted here.

After the second test period, in terms of oxidation, the largest number of statistically significant differences between average values concerned the pairs with the
PE oil (ME-PE, MS-PE, and PE-PS).

After being in use for three quarters of a year, the most homogenous pairs of oils in terms of oxidation were MS and PS, as well as MS and ME. After the last measurement period, it was noticed that for the variable - the degree of oxidation, there were statistically significant differences in the following oil pairs: ME-CE, ME-PE and PE-PS. It is worth mentioning that the situation after the fourth quarter was similar to the previous measurement period - the same oil groups maintained statistical significance for oxidation.

In general, most of the comparisons did not reveal any statistically significant differences. However, when looking at all four measuring periods, it can be noticed that for some of them at least, the comparisons almost reach statistical significance, thus suggesting a potential existence of differences.

Analyzing Table 3, it can be concluded that statistically significant differences between the mean values in each of the analyzed oil groups occur in all neighboring measurement periods, which could potentially indicate an acceleration of the upward trend in average oxidation values.

In order to obtain the full picture of oil and engine status, parameters such as kinematic viscosity, HTHS, CCS, TAN, TBN, oxidation, nitration, water content, and wear debris content were also measured. The research material obtained is very extensive and all of the changes in the above mentioned parameters have become the subject of other papers that have already been published [17-20, 29]. The most important findings discussed in those papers are as follows: the curves of kinematic viscosity changes in oil samples CE, MS, and PE are of similar shape, and after 12 months (in comparison to the kinematic viscosity of fresh oil) they increased by $20 \%, 16 \%, 27 \%$ (temp. $40{ }^{\circ} \mathrm{C}$ ) and $11 \%, 5 \%, 12 \%$ (temp. $100{ }^{\circ} \mathrm{C}$ ), respectively [17]. In the case of two oils-ME and PS, an initial decrease in viscosity from baseline level up to the mileage of about 10 thousand $\mathrm{km}$ was observed, then the viscosity started to increase [17]. The HTHS viscosity in the oil groups after 12 months, when compared with HTHS viscosity of fresh oil, increased by ca. 10\% [18]. All of the analyzed oil groups showed an upward trend in the dynamic viscosity at $-30{ }^{\circ} \mathrm{C}$ compared with the 
Table 3 The mean values, standard deviations, and * $p$ values for oxidation.

\begin{tabular}{|c|c|c|c|c|c|c|c|}
\hline \multirow{2}{*}{$\begin{array}{c}\text { Oil } \\
\text { group }\end{array}$} & & Quarter 1 & Quarter 2 & Quarter 2 & Quarter 3 & Quarter 3 & Quarter 4 \\
\hline & $N$ & 4 & 4 & 4 & 3 & 3 & 3 \\
\hline \multirow{2}{*}{$\mathrm{CE}$} & $\bar{x}(s)$ & $0.11(0.04)$ & $0.21(0.03)$ & $0.21(0.03)$ & $0.27(0.03)$ & $0.27(0.03)$ & $0.35(0.04)$ \\
\hline & $p$ & \multicolumn{2}{|c|}{0.014} & \multicolumn{2}{|c|}{0.024} & \multicolumn{2}{|c|}{0.013} \\
\hline \multirow{3}{*}{ PS } & $\bar{x}(s)$ & $0.11(0.01)$ & $0.17(0.01)$ & $0.17(0.01)$ & $0.24(0.03)$ & $0.24(0.03)$ & $0.31(0.03)$ \\
\hline & $p$ & \multicolumn{2}{|c|}{0.001} & \multicolumn{2}{|c|}{0.028} & \multicolumn{2}{|c|}{0.001} \\
\hline & $N$ & 5 & 5 & 5 & 5 & 5 & 5 \\
\hline \multirow{2}{*}{$\mathrm{ME}$} & $\bar{x}(s)$ & $0.11(0.02)$ & $0.18(0.02)$ & $0.18(0.02)$ & $0.19(0.03)$ & $0.19(0.03)$ & $0.25(0.06)$ \\
\hline & $p$ & \multicolumn{2}{|c|}{$\leq 0.001$} & \multicolumn{2}{|c|}{0.005} & \multicolumn{2}{|c|}{0.016} \\
\hline \multirow{2}{*}{ MS } & $\bar{x}(s)$ & $0.09(0.03)$ & $0.15(0.05)$ & $0.15(0.05)$ & $0.21(0.07)$ & $0.21(0.07)$ & $0.28(0.09)$ \\
\hline & $p$ & \multicolumn{2}{|c|}{0.003} & \multicolumn{2}{|c|}{0.008} & \multicolumn{2}{|c|}{0.003} \\
\hline \multirow{2}{*}{ PE } & $\bar{x}(s)$ & $0.13(0.01)$ & $0.23(0.03)$ & $0.23(0.03)$ & $0.31(0.04)$ & $0.31(0.04)$ & $0.39(0.04)$ \\
\hline & $p$ & \multicolumn{2}{|c|}{$\leq 0.001$} & \multicolumn{2}{|c|}{0.001} & \multicolumn{2}{|c|}{$\leq \mathbf{0 . 0 0 1}$} \\
\hline
\end{tabular}

$N$ - the number of samples tested, $x$ - arithmetic average, $s-$ standard deviation, $p-p$-value, ${ }^{*} p$-value resulting from the application of Student's t test for dependent samples

baseline value, and the sharpest increases (69\%) were observed in the PE group, while the lowest in the ME group (36\%). The acid number, which for fresh oils ranged from 1.29 to $1.78 \mathrm{mgKOH} / \mathrm{g}$, increased significantly over the entire period of use [19]. Each time the changes occurred, they were of approximately linear character. The greatest increase-above $6.6 \mathrm{mgKOH} / \mathrm{g}$ - in the acid number (in comparison to the initial value) was observed for the following oils: MS 018361, PS 018784, PE 018689, and MS 018817.

\section{Modeling alterations in the values of engine oil factors}

In the first phase of modelling the level of oxidation, the plausible limit value was determined [30,31]. Then for each oil a visual rating of the ratios between the mileage values and changes in oil parameter value was carried out. On this basis it was agreed that the linear relationship was appropriate.

Table 4 contains model estimates of intercepts $(A)$ and slopes (B). $p$-values for the hypotheses stating zero value of the slopes and the values of standard deviations of the (Se) residuals are also provided.

Results show that each parameter estimate was significantly different from zero $(p<0.05)$. The slope describes the average change of a given oil parameter
Table 4 The outcomes of the estimation of linear regression model for oxidation.

\begin{tabular}{ccccc}
\hline Oil code & $A$ & $B$ & $p$ & Se \\
\hline CE & 0.043 & 0.022 & 0.000 & 0.029 \\
ME & 0.053 & 0.017 & 0.000 & 0.019 \\
MS & 0.035 & 0.022 & 0.000 & 0.020 \\
PE & 0.038 & 0.024 & 0.000 & 0.033 \\
PS & 0.031 & 0.019 & 0.000 & 0.025 \\
\hline
\end{tabular}

attributed to an increase in the mileage by $1,000 \mathrm{~km}$. Hence, the slope greater than zero means the positive relation between the mileage and oil parameter values, whereas the slope smaller than zero stands for the reverse situation.

The estimated regression equation has the following linear form $Y=A+B X$ which allows for calculations of point predictions of the average oil parameter value $(Y)$ for any mileage value $(X)$. The $A$ and $B$ values are shown in Table 4. It is however worth remembering that reliable predictions can be made for $X$ values that were observed. These predictions are burdened with the smallest margin of error, whereas the extrapolation for mileages much bigger than observed can be burdened with a larger margin of error since these extrapolations are not fully supported by the data.

Figure 3 presents empirical data and point predictions for the mileage in the range of (0-16) thousand 

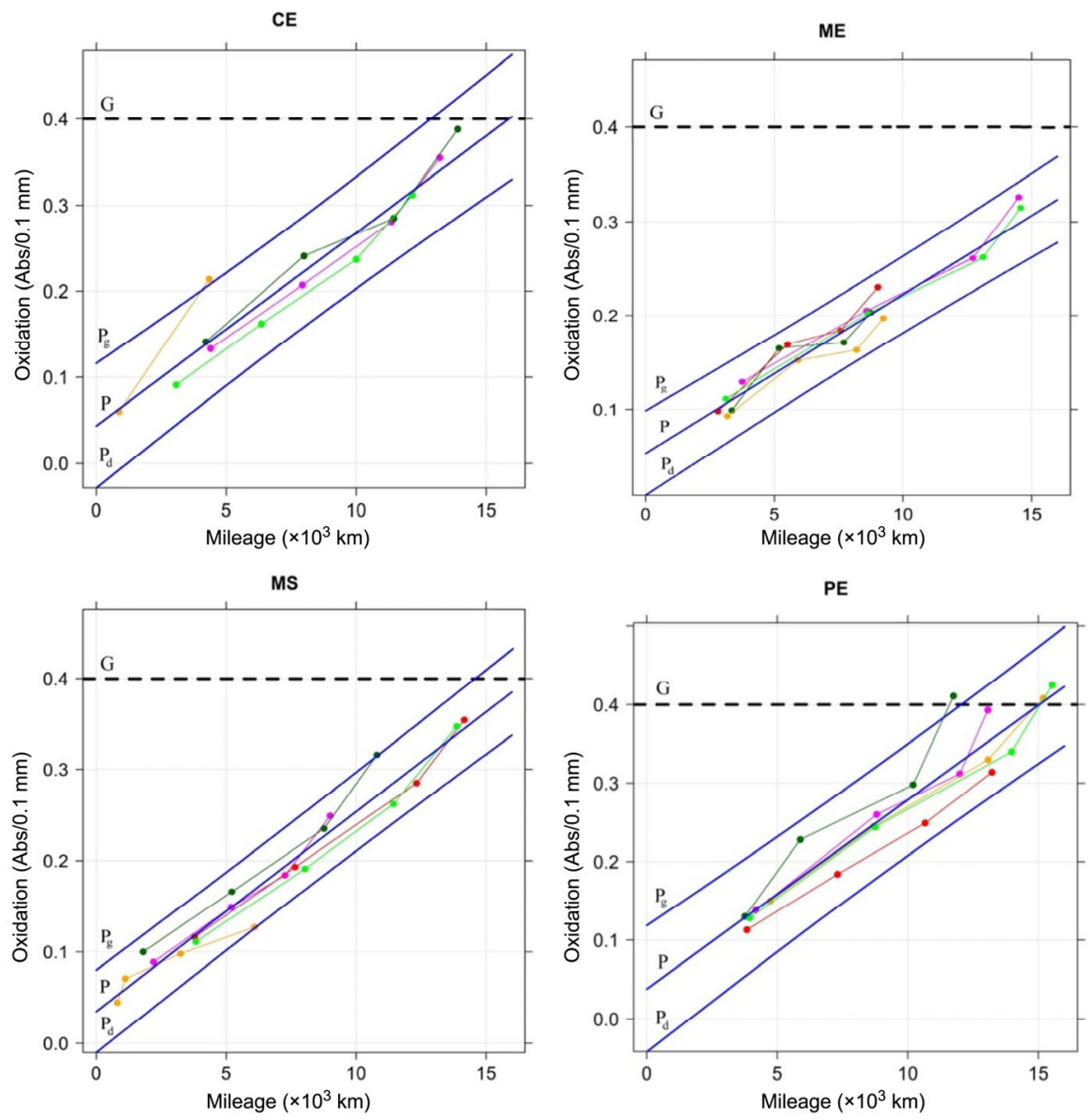

PS

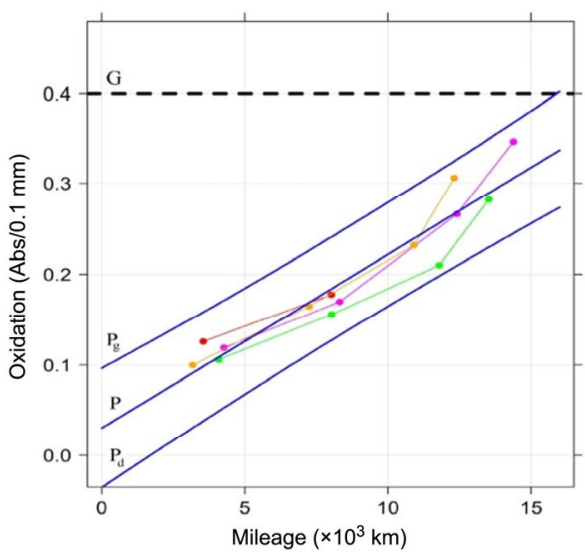

$\Rightarrow P$-single point predictive

$\Rightarrow P_{\mathrm{d}}$-lower limit of the $95 \%$ prediction interval

$\Rightarrow P_{\mathrm{g}}$-upper limit of the $95 \%$ prediction interval

$\Rightarrow G$-the limit value

Fig. 3 Observed data and model predictions for mileage from zero to 16 thousand kilometers.

kilometers (central line). The details regarding applied statistical (i.e., point predictions, the boundaries of 95\% of prediction intervals) were described in Ref. [15]. Analyzing the variations in the oxidation level obtained from the research findings and point predictions (Fig. 3), it was noticed that the changes taking place in time (showing approximately linear character) affected the very narrow prediction ranges for all groups of engine oils tested.

The narrowest width between the curves determining the limits of $95 \%$ of the prediction sections was detected in oils from the MS group; consequently, making predictions for mileages greater than those observed can be burdened with a relatively low margin of error. 
Regarding the models obtained for the ME and PS oil groups, it should be noted that they are burdened with the largest prediction error, because the prediction intervals have the largest width. It was noted that the PE group of oils exhibited the lowest resistance to oxidation. These oils reached the threshold level of 0.4 (Abs/0.1 mm) after merely 15,000 km. The best resistance to degradation caused by oxidation was found for the ME group of oils. From the very beginning of the test, a gradual increase in the degree of oxidation was observed, so it may be assumed that the extrapolation for mileages larger than those observed would probably be burdened with a relatively low error.

\section{Discussion}

Engine oil degradation is a complex process. As the oil ages, changes related to the depletion of additives, oxidation, or nitration as well as viscosity grade can be observed. Additionally, the process of degradation is influenced by solid impurities and contamination by fuel, soot, or water. At the same time, these factors influence one another, e.g., oil viscosity grade increases due to high molecular weight and polymerization (oxidation) rate of oils. In their study, Heredia-Cancino et al. have shown that even though the level of oxidation in the simulated samples of the oil was increasing until it reached a critical level, the viscosity grade did not increase, as other variables (e.g., fuel dilution) might have counteracted the effect caused by the level of oxidation [32]. As showed by Notay et al., changes resulting from oil degradation can influence the oil film thickness and thus affect friction in the piston rings-cylinder system [33]. Based on the presented results, it should be noted that there is limited knowledge on how engine lubricant degradation that occurs with time (mostly by the process of oxidation) influences tribological behavior in piston ring pack. It should also be taken into consideration that the analysis of tribological parameters is not sufficient to determine the lifespan of oil during its use. Despite the fact that FTIR analysis and the study of dynamic viscosity can serve as a warning about the need for oil change, tribological behavior (e.g., the coefficient of friction (COF)) may indicate otherwise. However, the COF can suddenly change due to depletion of additives, which may result in serious engine damage [33].

From the beginning of testing, all analyzed groups of oils have shown a similar upward trend in relation to the oxidation parameter. Nevertheless, the most perpendicular shape was noticed in the oil group PE, whereas the smoothest in the oil group ME and PS, it can therefore be concluded that ME and PS oils are characterized by the highest resistance to oxidation under real operating conditions. Furthermore, for all analyzed samples, a positive correlation was observed between the tested parameter and the number of kilometers traveled over the entire period of oil use.

\section{Conclusions}

The main purpose of this study was to describe variations in the oxidation of engine oil during operation. The research findings can contribute to a better understanding of the functioning of engine oils as well as to improvements in sensor assembly consisting of an IR source (applicable to the selected category of engine oil $5 \mathrm{~W}-30$ ). The major recapitulations of this study are as follows:

The FTIR spectra confirmed that the aging changes in the investigated engine oils, are caused mainly by oxidation. After twelve months of operation, and four measuring points, the largest number of statistically significant differences between average values concerned such pairs in which PE or CE oil was found (e.g., PE-ME, MS-PE, PS-PE, ME-CE, and PS-CE). Statistical analysis supported in affirming that the PE and CE oil groups were the most homogeneous of all. Statistically significant differences between the average values in each of the analyzed oil groups were observed in all neighboring measurement periods, which may potentially point to an acceleration of the upward trend for oxidation mean values.

The collected data formed the basis for the creation of a statistical model, which could be applied in the analysis of engine oils during operation. Very narrow prediction ranges of the oils in the MS group may contribute to high reliability of predictions for the unmeasured mileages. It was observed that the PE oil group showed the lowest resistance to oxidation - the 
threshold level of $0.4(\mathrm{Abs} / 0.1 \mathrm{~mm})$ was reached after merely $15,000 \mathrm{~km}$ traveled. The best resistance to degradation caused by oxidation was observed in oils from the ME group (0.4 Abs/0.1 mm, mileage over 20,000 km-extrapolation).

As there is still a wide scope for further research, the authors now plan to extend the analysis and include oils of other viscosity categories (e.g., 5W40 and 10W40), as this would make it possible to check whether the proposed predictive model has a universal dimension.

Thanks to the proposed equation, drivers can easily check every value of the level of oxidation and predict engine oil behavior under driving conditions. Nevertheless, the model presented in Section 5 cannot be used for predicting oxidation behavior universally since for a specific lubricant, the intercept and slope of the linear function have to be determined individually by experiments. The proposed model can be used only for oils that correspond to the characteristics tested in our article (viscosity class 5W-30, urban operation, etc.).

Despite these limitations, it has been proven that it is possible to develop a statistical model that predicts oxidation behavior; that is why, further research may contribute to the development of a universal model.

\section{Acknowledgements}

The publication was funded by appropriations of the Faculty of Production Engineering University of Life Sciences in Lublin, and the Faculty of Commodity Science, Cracow University of Economics, within the framework of grants to maintain the research potential. All laboratory tests for this study were conducted at the Oil and Gas Institute in Kraków - the National Research Institute.

Open Access: This article is licensed under a Creative Commons Attribution 4.0 International License, which permits use, sharing, adaptation, distribution and reproduction in any medium or format, as long as you give appropriate credit to the original author(s) and the source, provide a link to the Creative Commons licence, and indicate if changes were made.

The images or other third party material in this article are included in the article's Creative Commons licence, unless indicated otherwise in a credit line to the material. If material is not included in the article's Creative Commons licence and your intended use is not permitted by statutory regulation or exceeds the permitted use, you will need to obtain permission directly from the copyright holder.

To view a copy of this licence, visit http://creativecommons.org/licenses/by/4.0/.

\section{References}

[1] Krasodomski W, Żółty M. Influence of the chemical structure on results of the determination an antioxidant in lubricating oil. Prace Naukowe INiG-PIB 201: 105-117(2015)

[2] Al-Ghouti M A, Al-Degs Y S, Amer M. Application of chemometrics and FTIR for determination of viscosity index and base number of motor oils. Talanta 81(3): 1096-101 (2010)

[3] Zhu X L, Zhong C, Zhe J. Lubricating oil conditioning sensors for online machine health monitoring - A review. Tribiol Int 109: 473-484 (2017)

[4] Wang S S. A physical model for the engine oil condition sensor. Tribol Trans 44(3): 411-416 (2001)

[5] Van De Voort F R, Sedman J, Cocciardi R A, Pinchuk D. FTIR condition monitoring of in-service lubricants: Ongoing developments and future perspectives. Tribol Trans 49(3): 410-418 (2006)

[6] Bassbasi M, Hafid A, Platikanov S, Tauler R, Oussama A. Study of motor oil adulteration by infrared spectroscopy and chemometrics methods. Fuel 104: 798-804 (2013)

[7] Kupareva A, Mäki-Arvela P, Grénman H, Eränen K, Sjöholm R, Reunanen M, Murzin D Y. Chemical characterization of lube oils. Energy Fuels 27(1): 27-34 (2013)

[8] Zzeyani S, Mikou M, Naja J, Elachhab A. Spectroscopic analysis of synthetic lubricating oil. Tribol Int 114: 27-32 (2017)

[9] Sejkorová M, Hurtová I, Glos J, Pokorny J. Definition of a motor oil change interval for high-volume diesel engines based on its current characteristics assessment. Acta Univ Agric Silvic Mendelianae Brun 65(2): 481-490 (2017)

[10] Adams M J, Romeo M J, Rawson P. FTIR analysis and monitoring of synthetic aviation engine oils. Talanta 73(4): 629-634 (2007)

[11] Dong J, Van De Voort F R, Yaylayan V, Ismail A, Pinchuk D, Taghizadeh A. Determination of total base number (TBN) in lubricating oils by mid-FTIR spectroscopy. Lubr Eng 57(11): 24-30 (2001). 
[12] Al-Ghouti M A, Al-Atoum L. Virgin and recycled engine oil differentiation: A spectroscopic study. J Environ Manag 90(1): 187-195 (2009)

[13] Besser C, Dörr N, Novotny-Farkas F, Varmuza K, Allmaier G. Comparison of engine oil degradation observed in laboratory alteration and in the engine by chemometric data evaluation. Tribol Int 65: 37-47 (2013)

[14] Ng E P, Mintova S. Quantitative moisture measurements in lubricating oils by FTIR spectroscopy combined with solvent extraction approach. Microchem J 98(2): 177-185 (2011)

[15] De Rivas B L, Vivancos J L, Ordieres-Meré J, Capuz-Rizo $\mathrm{S}$ F. Determination of the total acid number (TAN) of used mineral oils in aviation engines by FTIR using regression models. Chemom Intell Lab Syst 160: 32-39 (2017)

[16] Agoston A, Schneidhofer C, Dörr N, Jakoby B. A concept of an infrared sensor system for oil condition monitoring. Elektrotechnik Und Informationstechnik 125(3): 71-75 (2008)

[17] Wolak A, Zając G. The kinetics of changes in kinematic viscosity of engine oils under similar operating conditions. Eksploat i Niezawodn - Maint Reliab 19(2): 260-267 (2017)

[18] Wolak A. Statistical analysis of HTHS viscosity rating of present-day engine oils. Tribol Trans 62(1): 34-41 (2019)

[19] Wolak A. Changes in lubricant properties of used synthetic oils based on the total acid number. Meas Control 51(3-4): 65-72 (2018)

[20] Wolak A. TBN performance study on a test fleet in real-world driving conditions using present-day engine oils. Measurement 114: 322-331 (2018)

[21] Wolak A, Zając G, Kumbár V. Evaluation of engine oil foaming tendency under urban driving conditions. Eksploat i Niezawodn 20(2): 229-235 (2018)

[22] ASTM E2412-10. Standard practice for condition monitoring of in-service lubricants by trend analysis using Fourier transform infrared (FT-IR). ASTM Int, 2010.

Artur WOLAK. He graduated from the Faculty of

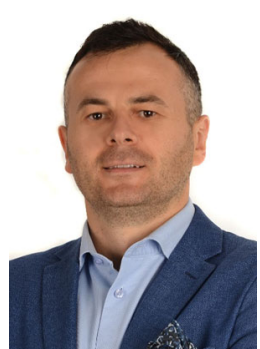
Commodity Science of the Cracow University of Economics in 2009. He received his Ph.D. degree in 2014. His current position is associate professor at the Department of Quality and Safety of Industrial Products at the Cracow University
[23] Coates J. Interpretation of infrared spectra, a practical approach. In Encyclopedia of Analytical Chemistry. Wiley, 2006.

[24] Robinson N, Hons B S. Monitoring oil degradation with infrared spectroscopy. Wear Check-Techn Bull 18: 1-8 (2000)

[25] Trujillo G. Resetting oil analysis parameters for changing diesel engines. Pract Oil Anal 01-02: 10-16 (2004)

[26] Pinchuk D, Akochi-Koblé E, Cocciardi R A, Pinchuk J, Van de Voort F R, Sedman J. Demystifying and understanding your lubricants using Ft-Ir spectroscopic analysis. In Proceedings of Lubrication Excellence Conference, Columbus Ohio, 2006.

[27] Mayer A. Understanding time-dependent limits. Pract Oil Anal 11-12: 12-17 (2005)

[28] Forsthoffer W E. Preventive and predictive maintenance best practices. In Forsthoffer's Best Practice Handbook for Rotating Machinery. Forsthoffer W E, Ed. Amsterdam, Boston, MA: Elsevier, 2011: 563-576.

[29] Wolak A, Zając G. Cold cranking viscosity of used synthetic oils originating from vehicles operated under similar driving conditions. Adv Mech Eng 10(11): 1-12 (2018)

[30] Kral Jr J, Konecny B, Kral J, Madac K, Fedorko G, Molnar V. Degradation and chemical change of longlife oils following intensive use in automobile engines. Measurement 50: 34-42 (2014)

[31] Urzędowska W, Stępień Z. Wybrane zagadnienia dotyczące zmian właściwości silnikowego oleju smarowego w eksploatacji. Nafta-Gaz 68(12): 1102-1110, 918-919 (2012)

[32] Heredia-Cancino J A, Ramezani M, Álvarez-Ramos M E. Effect of degradation on tribological performance of engine lubricants at elevated temperatures. Tribol Int 124: 230-237 (2018)

[33] Notay R S, Priest M, Fox M F. The influence of lubricant degradation on measured piston ring film thickness in a fired gasoline reciprocating engine. Tribol Int 129: 112-123 (2019)

of Economics. His research projects focus on improving the accuracy of assessment of physicochemical changes which occur during actual engine operation, predicting car drivers' behaviour, predicting environmental impact and damage, and testing assuming the measurement of electrical parameters of new and used motor oils. He is the author of 30 publications in scientific journals 


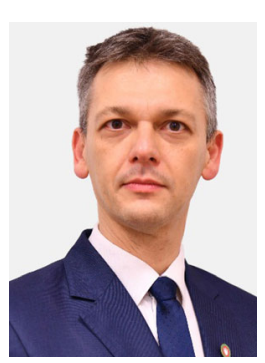

Grzegorz ZAJĄC. He received his M.S. degree in mechanical engineering from Lublin University of Technology Poland in 1998 and Ph.D. degree in agriculture engineering from University of Life

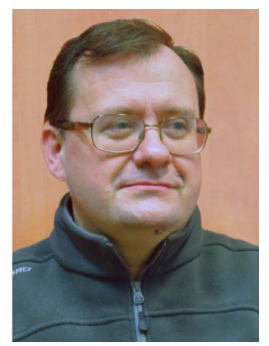

Wojciech KRASODOMSKI. He graduated from the Faculty of Chemistry of the Jagiellonian University in Krakow in 1991. He received his Ph.D. degree in 1998. In 1999, he was on a fellowship at the National Institute of Researches
Science in Lublin, Poland, in 2006. His current position is a professor and the Head of the Department of Power Engineering and Transportation. His research areas cover the problems of using engine oils and renewable energy technologies.

in Inorganic Materials in Tsukuba, Japan. He has been working at ING-PIB since 2002. Specialization: chemistry and technology of additives, analysis of fuels and petroleum products, and degradation processes of lubricants and fuels during exploitation. He is the author of over 50 publications in scientific journals and 20 patents and patent applications. 